Check for updates

Cite this: RSC Adv., 2018, 8, 4340

Received 11th December 2017 Accepted 10th January 2018

DOI: $10.1039 / c 7 r a 13225 e$

rsc.li/rsc-advances

\section{Earth-abundant $\mathrm{Fe}_{1-x} \mathrm{~S}$ aS-doped graphene oxide nano-micro composites as high-performance cathode catalysts for green solar energy utilization: fast interfacial electron exchange}

\begin{abstract}
Yueqiang Li, ${ }^{\text {ab }}$ Jie Yin, ${ }^{a}$ Chaofan $\mathrm{Chu}^{a}{ }^{a}$ Ning Sui, ${ }^{\mathrm{C}}$ Shaozhen Shi, ${ }^{a}$ Jiazhen Wei, ${ }^{a}$

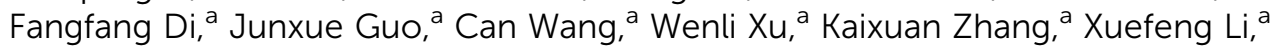
Tong Guo, ${ }^{a}$ Baoli Chen, ${ }^{a}$ Yingtian Zhang, ${ }^{a}$ Denghu Wei, ${ }^{a}$ Hongguo Hao, ${ }^{a}$ Xinting Wei, ${ }^{a}$ Xianxi Zhang, ${ }^{a}$ Jinsheng Zhao, ${ }^{a}$ Huawei Zhou (DD *a and Shuhao Wang (D) *a

In the process of conversion of solar energy into electricity and fuel, efficient electrocatalysts are indispensable. Rieske iron-sulfur protein and FeS catalysts play an important role in natural photosynthesis (NPS), and in artificial photoelectrochemical cells, respectively. Nano-micro composite catalysts (NMCCS) possess not only high catalytic activity but also fast electron transport. Herein, we prepared a nano-micro composite (NMC) of $\mathrm{Fe}_{1-x} \mathrm{~S}$ nanoparticles decorated on sulfur-doped graphene oxide (S-GO) sheets (namely, $\mathrm{Fe}_{1-x} \mathrm{~S}(\mathrm{~S}-\mathrm{GO}-\mathrm{NMC}$ ) to be used as a cathode in dye-sensitized solar cells (DSCs). The GO effectively inhibit the aggregation of $\mathrm{Fe}_{1-x} \mathrm{~S}$ nanoparticles. Notably, DSCs based on an $\mathrm{Fe}_{1-x} \mathrm{~S}$ (AS-GO-NMC cathode achieved a high solar-to-electrical conversion efficiency up to $7.23 \%$. The conversion efficiency is, to our knowledge, one of the highest efficiencies for DSCs based on an FeS or $\mathrm{FeS}_{2}$ cathode. Although the $\mathrm{Fe}_{1-x} \mathrm{~S} @ \mathrm{~S}-\mathrm{GO}-\mathrm{NMC}$ exhibited a low thermodynamic possibility for redox reactions, it showed a higher kinetic rate than that of $\mathrm{Pt}$ for the charge transfer between the reaction medium and the cathode. This indicates that a fast electron exchange process occurs at the interface between the reaction and the cathode. The value of the time constant $(\tau)$ corresponding to the charge exchange resistance based on $\mathrm{Fe}_{1-x} \mathrm{~S}(\mathrm{SS}-\mathrm{GO}-\mathrm{NMC}(0.0215 \mathrm{~ms})$ was smaller than that obtained with $\mathrm{Pt}$ (0.261 ms). Therefore, we ascribed the superior performance of the photoelectrochemical device based on $\mathrm{Fe}_{1-x} \mathrm{~S}$ (CS-GO-NMC to its good electrocatalytic performance. The results are of great interest for fundamental research and for practical applications of $\mathrm{FeS}$ and $\mathrm{FeS}_{2}$ and their composites in the solar splitting of water, artificial photoelectrochemical cells, and electrocatalysts.
\end{abstract}

\section{Introduction}

With the continuous increase in consumption of fossil energy, environmental pollution ${ }^{1}$ and the energy crisis ${ }^{2}$ are becoming more and more stringent. As an alternative, considerable efforts have been devoted to developing new renewable and clean energy resources. ${ }^{3}$ The effective development and use of these energy sources can greatly reduce the dependence on fossil fuels, which will consequently reduce environmental pollution. The use of renewable energy sources, such as wind energy, hydro energy, or geothermal energy, is restricted by specific

${ }^{a}$ School of Chemistry and Chemical Engineering, Shandong Provincial Key Laboratory of Chemical Energy Storage and Novel Cell Technology, College of Materials Science and Engineering, Liaocheng University, Liaocheng 252000, China. E-mail: zhouhuaweiopv@163.com; shuhaowang@sohu.com

${ }^{b}$ Liaocheng Seismic Hydrochemistry Station, China

${ }^{c}$ College of Materials Science and Engineering, Qingdao University of Science and Technology, Qingdao 266042, China regional conditions. Solar energy offers the advantage of being available everywhere and at a lower cost. Therefore, the effective transformation and utilization of solar energy is a very promising direction in prospect. Solar energy can be converted into heat, ${ }^{4}$ electrical energy, ${ }^{5}$ or chemical energy (oxygen and carbohydrates are produced from water and carbon dioxide using sunlight). ${ }^{6}$ In the process of conversion of solar energy into electricity and fuel, efficient electrocatalysts are essential. ${ }^{7}$ For example, in a dye-sensitized solar cell and a quantum dot solar cell, redox mediators (sulfur, iodine, cobalt, ferrocene) are recycled by efficient electrocatalysts. ${ }^{8}$ In the process of watersplitting, the role of an efficient electrocatalyst is also indispensable. ${ }^{9}$

The Rieske iron-sulfur protein plays an important role in natural photosynthesis (NPS). ${ }^{10}$ In addition, FeS has great potential in dye-sensitized solar cell applications and quantum dots-sensitized solar cells (QDSCs). Quan et al. reported the application of three-dimensional (3D) FeS nanospheres as 
electrocatalysts for the $\mathrm{S}^{2-} / \mathrm{S}_{n}{ }^{2-}$ redox reaction in quantum dots-sensitized solar cells: a power conversion efficiency (PCE) of $3.34 \%$ was achieved. ${ }^{\mathbf{1 1}}$ FeS was deposited on 3D carbon scaffolds to develop electrocatalysts for the $\mathrm{S}^{2-} / \mathrm{S}_{n}{ }^{2-}$ redox reaction in quantum dots-sensitized solar cells, demonstrating a power conversion efficiency of $4.58 \% .{ }^{12}$ QDSCs based on an FeS/nickel foam counter electrode achieved a PCE of $4.39 \% .{ }^{13}$ Recently, $\mathrm{Wu}^{14}$ and Batmunk $\mathrm{h}^{\mathbf{1 5}}$ demonstrated the application of a hybrid electrocatalyst $\mathrm{SGN}^{-\mathrm{FeS}_{2}}$ (sulfur-doped graphene with $\mathrm{FeS}_{2}$ microspheres) and polypyrrole/FeS in DSCs. An SGN$\mathrm{FeS}_{2}$ and polypyrrole/FeS-based device displayed PCEs of 7.48\% and $8.1 \%$, respectively. In addition, the performance of carbon (such as graphene)-based cathodes in DSCs was also good. ${ }^{\mathbf{1 6 - 2 3}}$

Nano-micro composite catalysts (NMCCs) not only give higher catalytic activity but also fast electron transport. ${ }^{18}$ Herein, we report the one-pot hydrothermal synthesis of a nano-micro composite (NMC) composed of $\mathrm{Fe}_{1-x} \mathrm{~S}$ nanoparticles decorated on sulfur-doped graphene oxide (S-GO) sheets (namely, $\mathrm{Fe}_{1-x} \mathrm{~S} @ S-G O-N M C$ ). The graphene oxide substrate in NMC inhibited the aggregation of $\mathrm{Fe}_{1-x} \mathrm{~S}$ nanoparticles. Notably, DSCs based on an $\mathrm{Fe}_{1-x} \mathrm{~S} @ S-G O-N M C$ cathode achieved a high solar-to-electrical conversion efficiency up to $7.23 \%$ with an open circuit voltage $\left(V_{\text {oc }}\right)$ of $0.72 \mathrm{~V}$, a short circuit current density $\left(J_{\mathrm{sc}}\right)$ of $14.08 \mathrm{~mA} \mathrm{~cm} \mathrm{~cm}^{-2}$, and a fill factor (FF) of 0.72 . We ascribe the superior performance of an $\mathrm{Fe}_{1-x^{-}}$ S@S-GO-NMC based photoelectrochemical device to its excellent electrocatalytic performance.

\section{Experimental section}

\section{Preparation of $\mathrm{Fe}_{1-x} \mathrm{~S}$ agglomerated particles}

Typically, $0.003 \mathrm{~mol}$ of $\mathrm{FeCl}_{3} \cdot 6 \mathrm{H}_{2} \mathrm{O}$ were dissolved in $30 \mathrm{~mL}$ of deionized water by vigorous agitation. $0.045 \mathrm{~mol}$ of thioacetamide (TAA) were dissolved in $30 \mathrm{~mL}$ of deionized water by vigorous agitation. The above two solutions were mixed. The mixture was stirred for $0.5 \mathrm{~h}$ at room temperature and then transferred into a Teflon-lined autoclave. After being heated at $200{ }^{\circ} \mathrm{C}$ for $15 \mathrm{~h}$, the product was naturally cooled to room temperature. The product was washed three times with water and ethanol.

\section{Preparation of $\mathrm{Fe}_{1-x} \mathrm{~S}$ nanoparticles fixed on S-doped graphene oxide (GO) sheets (namely, $\left.\mathrm{Fe}_{1-x} \mathrm{~S} @ S-G O\right)$}

Graphene oxide (GO) was prepared using a modified Hummers' method. ${ }^{18}$ The specific synthesis method can be seen in our previous paper. ${ }^{\mathbf{1 8}}$ The obtained GO precipitates were dispersed in deionized water to obtain a $1 \mathrm{wt} \%$ GO dispersion. $2 \mathrm{~g}$ of $1 \mathrm{wt} \%$ GO dispersion were dispersed in $10 \mathrm{~mL}$ of deionized water by ultrasound. $0.81 \mathrm{~g}$ of $\mathrm{FeCl}_{3} \cdot 6 \mathrm{H}_{2} \mathrm{O}$ were dissolved in $30 \mathrm{~mL}$ of deionized water by vigorous agitation. Different quantities $(0.2340,1.1348,2.2546,3.3847,4.5045 \mathrm{~g})$ of TAA were dissolved in $20 \mathrm{~mL}$ of deionized water by vigorous agitation. The above three solutions were mixed. The mixture was stirred for $0.5 \mathrm{~h}$ at room temperature and then transferred into a Teflon-lined autoclave. After being heated at $200{ }^{\circ} \mathrm{C}$ for $15 \mathrm{~h}$, the product was naturally cooled to room temperature. The product was washed three times with water and ethanol.

\section{Photoanode preparation and cell fabrication}

A $12 \mu \mathrm{m}$ thick layer was deposited on FTO glass by printing 20 nm-sized $\mathrm{TiO}_{2}$ particles (P25, Degussa, Germany). ${ }^{24}$ The obtained film was sintered at $500{ }^{\circ} \mathrm{C}$. After cooling to $90{ }^{\circ} \mathrm{C}$, the $\mathrm{TiO}_{2}$ films were immersed in a solution of N719 dye $(5 \times$ $10^{-4} \mathrm{M}$ ) in acetonitrile/tert-butyl alcohol (1:1 volume ration) for $20 \mathrm{~h}$. For the $\mathrm{TiO}_{2}$ photoanode film treated with $\mathrm{TiCl}_{4}$, the films were immersed in $40 \mathrm{mM} \mathrm{TiCl}{ }_{4}$ solution at $70{ }^{\circ} \mathrm{C}$ for $30 \mathrm{~min}$ and then sintered at $500{ }^{\circ} \mathrm{C}$ for $30 \mathrm{~min}$. The triiodide/ iodide electrolyte for cell testing was composed of LiI (0.03 M), 1-butyl-3-methylimidazolium iodide $(0.6 \mathrm{M}), \mathrm{I}_{2}$ $(0.03 \mathrm{M})$, 4-tert-butyl pyridine $(0.5 \mathrm{M})$, guanidinium thiocyanate in acetonitrile $(0.1 \mathrm{M})$. DSCs were assembled with a $\mathrm{TiO}_{2}$ photoanode with the corresponding counter electrode sandwiching the redox couple in the electrolyte. Symmetrical cells with an effective area of $0.64 \mathrm{~cm}^{2}$ were analyzed in a Tafel-polarization test and through EIS experiments.

\section{Characterization}

To analyze the as-synthesized composite electrocatalyst, X-ray diffraction (XRD) patterns were acquired using a PANalytical $\mathrm{X}$ 'Pert diffractometer $(\mathrm{Cu} \mathrm{K} \alpha$ radiation at $\lambda=1.5406 \AA$ ) sampling at $5^{\circ} \mathrm{min}^{-1}, 36 \mathrm{kV}$ and $20 \mathrm{~mA}$. As-prepared micro or nanostructures were characterized and analyzed by scanning electron microscopy (SEM, Nova Nano SEM 450). The photocurrentvoltage performance of DSCs with $0.16 \mathrm{~cm}^{2}$ of photoanode film was measured without a metal mask by a Keithley digital source meter (Keithley 2400, USA) equipped with a solar simulator (IV5, PV Measurements, Inc., USA). EIS experiments were carried out with symmetrical electrodes in the dark using an electrochemical workstation (CHI760 Chenhua, China). Cyclic voltammetry (CV) was performed in a three-electrode configuration. The triiodide/iodide electrolyte for $\mathrm{CV}$ testing was composed of $\mathrm{LiI}(2 \mathrm{mM}), \mathrm{LiClO}_{4}(20 \mathrm{mM})$ and $\mathrm{I}_{2}(0.2 \mathrm{mM})$.

\section{Results and discussion}

In our experiments, $\mathrm{Fe}_{1-x} \mathrm{~S} @ \mathrm{~S}-\mathrm{GO}-\mathrm{NMC}$ was prepared using a simple one-pot solvothermal approach, as shown in Fig. 1. The amounts of $\mathrm{FeCl}_{3}$ and TAA in solution were 0.003 and $0.045 \mathrm{~mol}$. Meanwhile, $\mathrm{Fe}_{1-x} \mathrm{~S}$ particles were prepared as a reference. Details of the synthesis process are reported in the experimental section. The SEM images shown in Fig. 2a illustrate that $\mathrm{Fe}_{1-x} \mathrm{~S}$ agglomerated particles were seriously agglomerated. Fig. $2 \mathrm{~b}$ shows that the agglomeration of $\mathrm{Fe}_{1-x} \mathrm{~S}$ particles resulted in a non-uniform size (within the range of $500 \mathrm{~nm}$ to 2 microns) of the block or caking. The agglomerated $\mathrm{Fe}_{1-x} \mathrm{~S}$ blocks or cakings cover many catalytically active sites on the surface of each $\mathrm{Fe}_{1-x} \mathrm{~S}$ nanoparticle. In addition, the massive grain boundaries in the $\mathrm{Fe}_{1-x} \mathrm{~S}$ blocks could possibly inhibit electron transport. These two factors may be the reason for the poor performance of previously reported devices based on pure FeS. We tried to inhibit the aggregation of $\mathrm{Fe}_{1-x} \mathrm{~S}$ nanoparticles with GO. Fig. 2c 


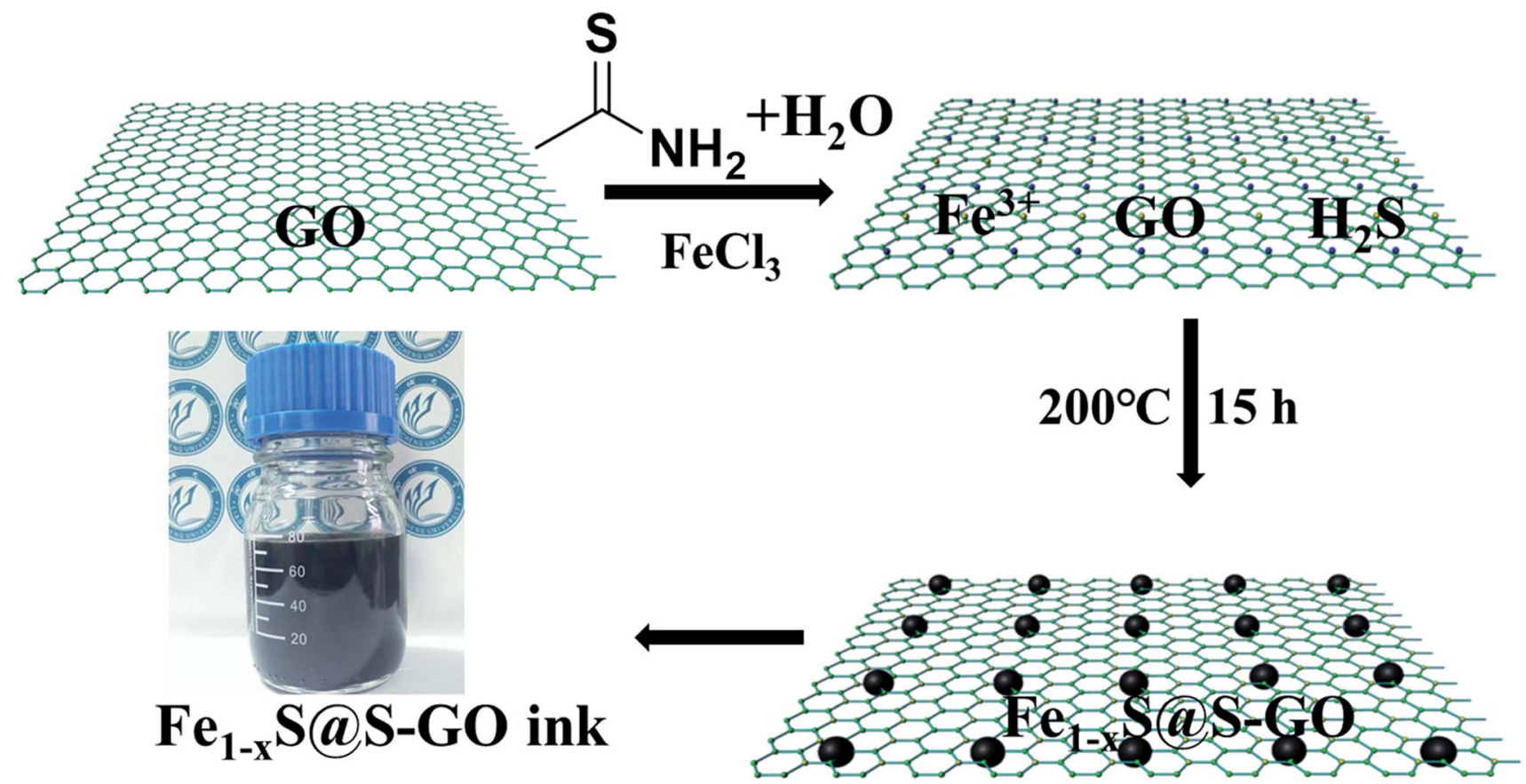

Fig. 1 Schematic diagrams illustrating the simple one-pot hydrothermal approach for preparing Fe ${ }_{1-x} S$ nanoparticles fixed on sulfur-doped graphene oxide (S-GO) sheets (namely, $\mathrm{Fe}_{1-x} \mathrm{~S}(\mathrm{~S}-\mathrm{GO}-\mathrm{NMC}$ ).

shows the 2D structure of GO prepared using the modified Hummers' method. ${ }^{24}$ The surface of GO flakes up to ten microns is very smooth with only few wrinkles. In the case of a conductive film or a composite substrate, the large size of GO is beneficial to reducing the boundaries in the thin film and helps to limit the recombination of the electrons at the boundaries, and thus increases the conductivity. The TEM images of $\mathrm{Fe}_{1-x} \mathrm{~S} @ S-G O-N M C$ (Fig. $2 \mathrm{~d}$ and e) show that $\mathrm{Fe}_{1-x} \mathrm{~S}$ nanoparticles were dispersed on the GO surface. Fig. 2e shows the sizes of $\mathrm{Fe}_{1-x} \mathrm{~S}$ nanoparticles dispersed on the RGO surface within the range of $40 \mathrm{~nm}$ to $350 \mathrm{~nm}$. Thus, the GO effectively inhibits the aggregation of $\mathrm{Fe}_{1-x} \mathrm{~S}$ nanoparticles. XRD patterns
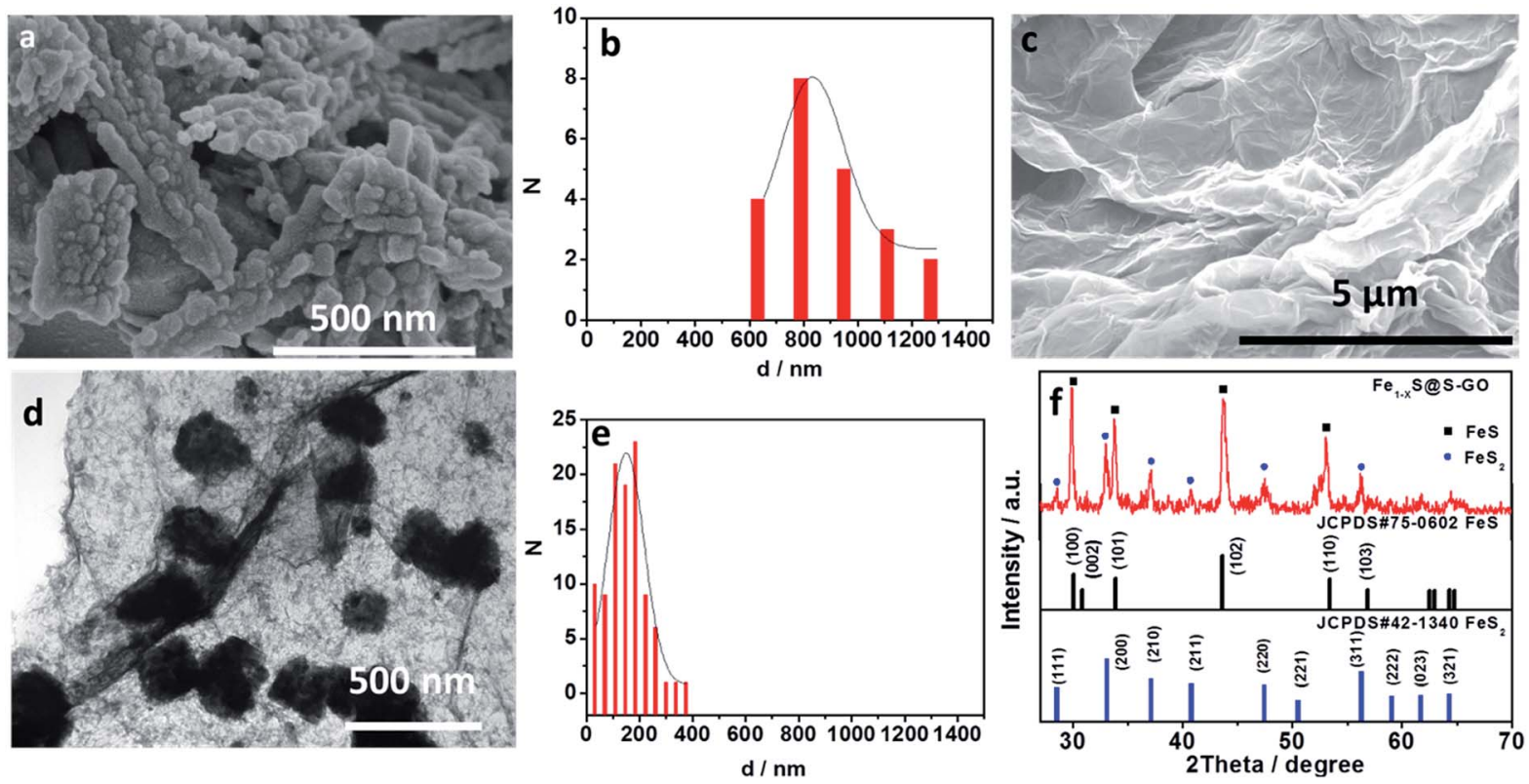

Fig. 2 (a) SEM images of as-prepared $\mathrm{Fe}_{1-x} \mathrm{~S}$ agglomerated nanoparticles; (b) Size distribution of as-prepared Fe $\mathrm{F}_{1-x} \mathrm{~S}$ agglomerated particles; (c) SEM images of as-prepared 2D GO sheets; (d) TEM images of as-prepared $\mathrm{Fe}_{1-x} \mathrm{~S}$ nanoparticles fixed on sulfur-doped graphene oxide (S-GO) sheets ( $\mathrm{Fe}_{1-x} \mathrm{~S}\left(\mathrm{SS}-\mathrm{GO}-\mathrm{NMC}\right.$ ); (e) size distribution of $\mathrm{Fe}_{1-x} \mathrm{~S}$ nanoparticles fixed on sulfur-doped graphene oxide (S-GO) sheets; (f) XRD patterns of as-prepared $\mathrm{Fe}_{1-x} \mathrm{~S}(\mathrm{~S}-\mathrm{GO}-\mathrm{NMC}$ powder. 


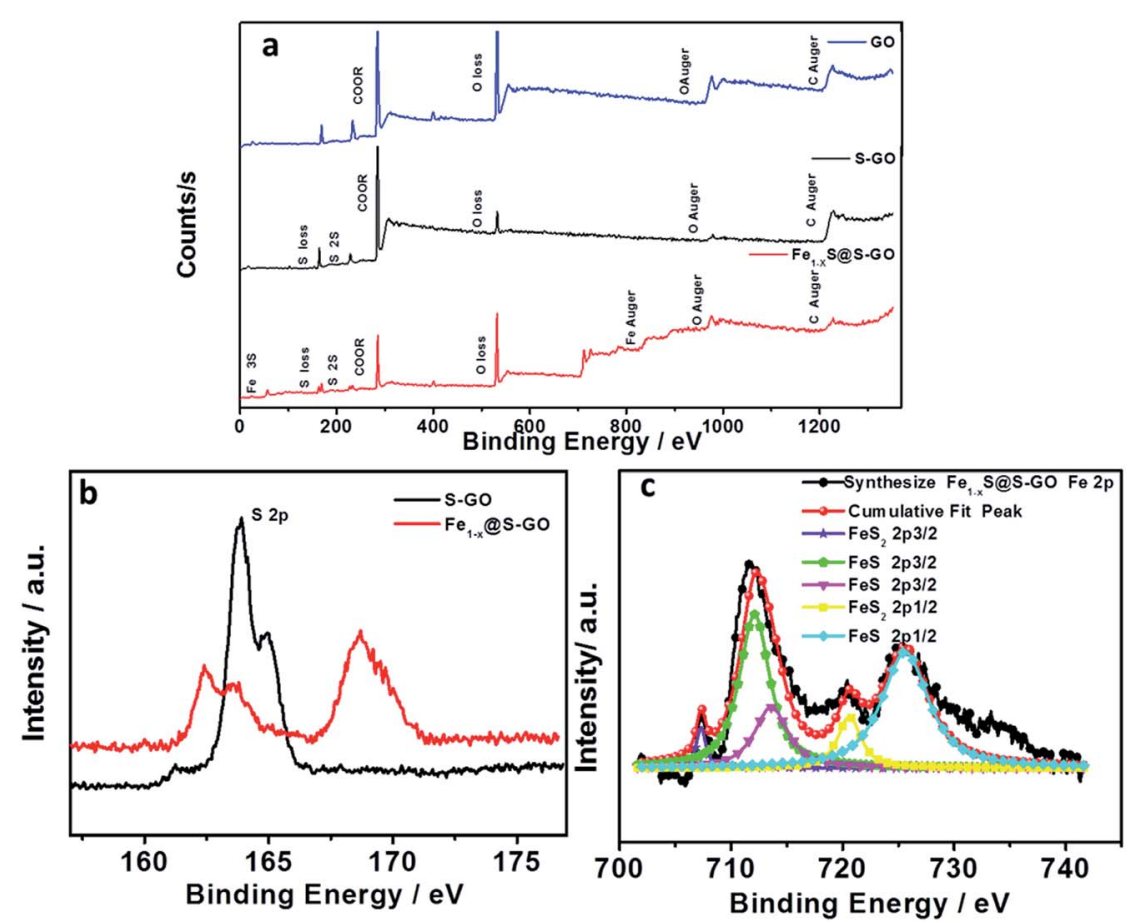

Fig. 3 (a) Full-range XPS spectra of GO (blue), S-GO (black) and Fe $e_{-x} \mathrm{~S}(\mathrm{~S}-\mathrm{GO}-\mathrm{NMC}$ (red). (b) Comparison of S 2p for S-GO (black) and $\mathrm{Fe}_{1-x} \mathrm{~S}\left(\mathrm{~S}-\mathrm{GO}-\mathrm{NMC}\right.$ (red). (c) Fe $2 \mathrm{p}$ spectra of Fe ${ }_{1-x} \mathrm{~S} @ \mathrm{~S}-\mathrm{GO}-\mathrm{NMC}$ (red).

of $\mathrm{Fe}_{1-x} \mathrm{~S} @ \mathrm{~S}-\mathrm{GO}-\mathrm{NMC}$ (Fig. 2f) show that $\mathrm{Fe}_{1-x} \mathrm{~S} @ \mathrm{~S}-\mathrm{GO}-\mathrm{NMC}$ displays.

FeS-FeS ${ }_{2}$ hybrid crystalline structure. Diffraction peaks at $30.0^{\circ}, 30.8^{\circ}, 33.8^{\circ}, 43.6^{\circ}$ and $53.3^{\circ}$ were attributed to the $(100)$, (002), (101), (102) and (110) planes, respectively, of the standard FeS nanocrystals with a hexagonal $\left(P 6_{3} / m m c\right)$ structure (JCPDS\#75-0602). Diffraction peaks at $28.5^{\circ}, 33.0^{\circ}, 37.2^{\circ}, 40.7^{\circ}$, $47.4^{\circ}$ and $56.2^{\circ}$ could be indexed to the (111), (200), (210), (211), (220) and (311) planes, respectively, of the standard $\mathrm{FeS}_{2}$ nanocrystals with a cubic [Pa-3(205)] structure (JCPDS\#42-1340).

To further determine the structure and composition of $\mathrm{Fe}_{1-x} \mathrm{~S} @ S-G O-N M C$, we conducted X-ray photoelectron spectroscopy (XPS) tests. The results are shown in Fig. 3. The full range of the XPS spectra of $\mathrm{Fe}_{1-x} \mathrm{~S} @ S-G O-N M C, \mathrm{~S}-\mathrm{GO}$ and GO is shown in Fig. 3a. The mole ratio of $\mathrm{FeCl}_{3} / \mathrm{TAA}=1 / 15$, so the excess TAA will react with GO to form S-GO. The obvious peaks at 162.4 and $168.7 \mathrm{eV}$ in the $\mathrm{S} 2 \mathrm{p}$ spectra of $\mathrm{Fe}_{1-x} \mathrm{~S} @ \mathrm{~S}-\mathrm{GO}-\mathrm{NMC}$ can be attributed to $\mathrm{S}$ in the $\mathrm{FeS}-\mathrm{FeS}_{2}$ hybrid crystalline structure. In addition, shoulder peaks at 163.8 and $164.9 \mathrm{eV}$ in the $\mathrm{S}$ 2p spectra of $\mathrm{Fe}_{1-x} \mathrm{~S} @ S-G O-N M C$ (as shown in Fig. $3 \mathrm{~b}$ ) can be observed. In order to assign shoulder peaks at 163.8 and $164.9 \mathrm{eV}$ in the $\mathrm{S} 2 \mathrm{p}$ spectra of $\mathrm{Fe}_{1-x} \mathrm{~S} @ S-G O-N M C$, we have synthesized S-GO with graphene oxide and TAA under the same experimental conditions as for $\mathrm{Fe}_{1-x} \mathrm{~S} @ S-G O-N M C$. The obvious S 2p peaks at 163.8 and $164.9 \mathrm{eV}$ can also be observed in the $\mathrm{S} 2 \mathrm{p}$ spectra of S-GO, as shown in Fig. 3b. Thus, shoulder peaks at 163.8 and $164.9 \mathrm{eV}$ in the $\mathrm{S} 2 \mathrm{p}$ spectra of $\mathrm{Fe}_{1-x} \mathrm{~S} @ \mathrm{~S}-\mathrm{GO}-$ NMC confirmed the formation of sulfur-doped graphene oxide in $\mathrm{Fe}_{1-x} \mathrm{~S} @ S-G O-N M C$. A complex energy distribution of Fe 2p photoelectrons was obtained and is shown in Fig. 3c. The spectrum could be fitted using the "XPS peak" software with Gaussian functions after subtraction of a Shirley background. The Fe 2 p spectrum could be fitted into four peaks which were associated with different $\mathrm{Fe} 2 \mathrm{p}$ in FeS and $\mathrm{FeS}_{2}{ }^{26,27}$ The fitting data for different peaks are listed in Table 1 . The main peaks at 712.1 and $725.4 \mathrm{eV}$ were attributed to FeS $2 \mathrm{p}_{3 / 2}$ and $2 \mathrm{p}_{1 / 2}$. The peaks at 707.3 and $720.6 \mathrm{eV}$ were attributed to $\mathrm{FeS}_{2} 2 \mathrm{p}_{3 / 2}$ and $2 \mathrm{p}_{1 / 2}$. As can be seen from the areas in Table $1, \mathrm{FeS}$ is the dominant component in the $\mathrm{Fe}_{1-x} \mathrm{~S} @ S-G O-N M C$. The results are in agreement with the intensity of the XRD diffraction. Thus, the synthesis mechanism of $\mathrm{Fe}_{1-x} \mathrm{~S} @ S-G O-N M C$ can be described as follow:

$$
\begin{gathered}
\mathrm{CH}_{3} \mathrm{CSNH}_{2}+\mathrm{H}_{2} \mathrm{O} \rightarrow \mathrm{CH}_{3} \mathrm{COONH}_{4}+\mathrm{H}_{2} \mathrm{~S} \\
\mathrm{FeCl}_{3}+\mathrm{H}_{2} \mathrm{~S} \rightarrow \mathrm{Fe}_{1-x} \mathrm{~S}+\mathrm{HCl}+\mathrm{S} \\
\mathrm{H}_{2} \mathrm{~S}+\mathrm{GO} \rightarrow \mathrm{S}-\mathrm{GO}
\end{gathered}
$$

In order to demonstrate the hypothesis that an $\mathrm{Fe}_{1-x} \mathrm{~S} @ S$ -

\begin{tabular}{|c|c|c|c|}
\hline Peak & Position & Index & Area \\
\hline Peak 1 & 707.3 & $\mathrm{FeS}_{2} 2 \mathrm{p}_{3 / 2}$ & 1205 \\
\hline Peak 2 & 712.1 & $\mathrm{FeS} 2 \mathrm{p}_{3 / 2}$ & 15003 \\
\hline Peak 3 & 720.6 & $\mathrm{FeS}_{2} 2 \mathrm{p}_{1 / 2}$ & 3808 \\
\hline Peak 4 & 725.4 & FeS $2 p_{1 / 2}$ & 17210 \\
\hline
\end{tabular}
GO-NMC cathode has a good electrocatalytic performance, we

Table 1 The fitting data for the Fe $2 \mathrm{p}$ spectrum in $\mathrm{Fe}_{1-x} \mathrm{~S} \mathrm{aS}-\mathrm{GO}-\mathrm{NMC}$ 
investigated the electrocatalytic performance and the electron transfer of $\mathrm{Fe}_{1-x} \mathrm{~S} @ S-G O . \mathrm{Fe}_{1-x} \mathrm{~S} @ S-G O$ ink was fabricated into a thin film electrode by spraying it onto a FTO/glass substrate. In our previous report, we optimized the catalyst loading in similar nano-micro composite catalysts $\left(\mathrm{Fe}_{3} \mathrm{O}_{4} @ \mathrm{RGO}\right)$. For $\mathrm{Fe}_{3} \mathrm{O}_{4} @ \mathrm{RGO}$, a layer thickness of $16 \mu \mathrm{m}$ is best. So we control the layer thickness of our cathode at $16 \mu \mathrm{m}$. Meanwhile, pyrolytic platinum was prepared for use as a cathode reference. Pyrolytic platinum was fabricated on FTO/glass by pyrolysis of a $0.16 \mathrm{wt} \% \mathrm{H}_{2} \mathrm{PtCl}_{6}$ aqueous solution. The obtained film was sintered at $450{ }^{\circ} \mathrm{C}$ for $1 \mathrm{~h}$. For EIS and Tafel characterizations, symmetrical cells were assembled using two identical cathodes filled with $\mathrm{I}_{3}{ }^{-} / \mathrm{I}^{-}$electrolytes and spaced by $40 \mu \mathrm{m}$ tape, as shown in Fig. 4a. The active area of the symmetrical cell was $0.64 \mathrm{~cm}^{2}$. The exchange current density $\left(J_{0}\right)$ in the Tafel region (as shown in Fig. 4b) is very closely related to the kinetic rate of charge transfer between the reaction medium and the cathode. Tafel polarization curves of symmetrical cells fabricated with two identical cathodes (mole ratios of $\mathrm{FeCl}_{3} / \mathrm{TAA}=1 / 1,1 / 5,1$ /
$10,1 / 15,1 / 20)$ are shown in Fig. $4 \mathrm{~b} . J_{0}$ for the cathode material synthesized with a mole ratio of $\mathrm{FeCl}_{3} / \mathrm{TAA}=1 / 1$ was $1.04 \mathrm{~mA} \mathrm{~cm}^{-2}$, which is lower than that based on $\mathrm{Pt}$ (1.16 $\mathrm{mA} \mathrm{cm}{ }^{-2}$ ). When the mole ratio of $\mathrm{FeCl}_{3} / \mathrm{TAA}$ was increased to $1 / 5,1 / 10,1 / 15$ and $1 / 20$, the values of $J_{0}$ also increased. The results indicated that the element of S-GO (formed by reaction between excess TAA and GO) in $\mathrm{Fe}_{1-x} \mathrm{~S} @ S-G O-N M C$ was beneficial for improving the kinetic rate of charge transfer between the reaction medium and the cathode. For $\mathrm{Fe}_{1-x} \mathrm{~S} @ S-G O-N M C$ synthesized with a mole ratio of $\mathrm{FeCl}_{3} / \mathrm{TAA}=1 / 15$, the $J_{0}\left(2.28 \mathrm{~mA} \mathrm{~cm}^{-2}\right)$ in the Tafel zone which resulted was remarkably higher than that of Pt $(1.16 \mathrm{~mA}$ $\mathrm{cm}^{-2}$ ), indicating a faster electron exchange at the interface between the reaction medium and the cathode. The larger $J_{0}$ well explains the high photovoltaic activity observed with the $\mathrm{Fe}_{1-x} \mathrm{~S} @ S-G O-N M C$ cathode. The $\mathrm{Fe}_{1-x} \mathrm{~S} @ S-G O-N M C$ cathode delivered a higher photocurrent density $\left(13.0 \pm 1.0 \mathrm{~mA} \mathrm{~cm}{ }^{-2}\right)$ compared to $\mathrm{Pt}\left(12.1 \pm 0.6 \mathrm{~mA} \mathrm{~cm} \mathrm{~cm}^{-2}\right)$, as shown in Table 2 . Thus, the $\mathrm{Fe}_{1-x} \mathrm{~S} @ \mathrm{~S}-\mathrm{GO}-\mathrm{NMC}$ cathode allows for an accelerated
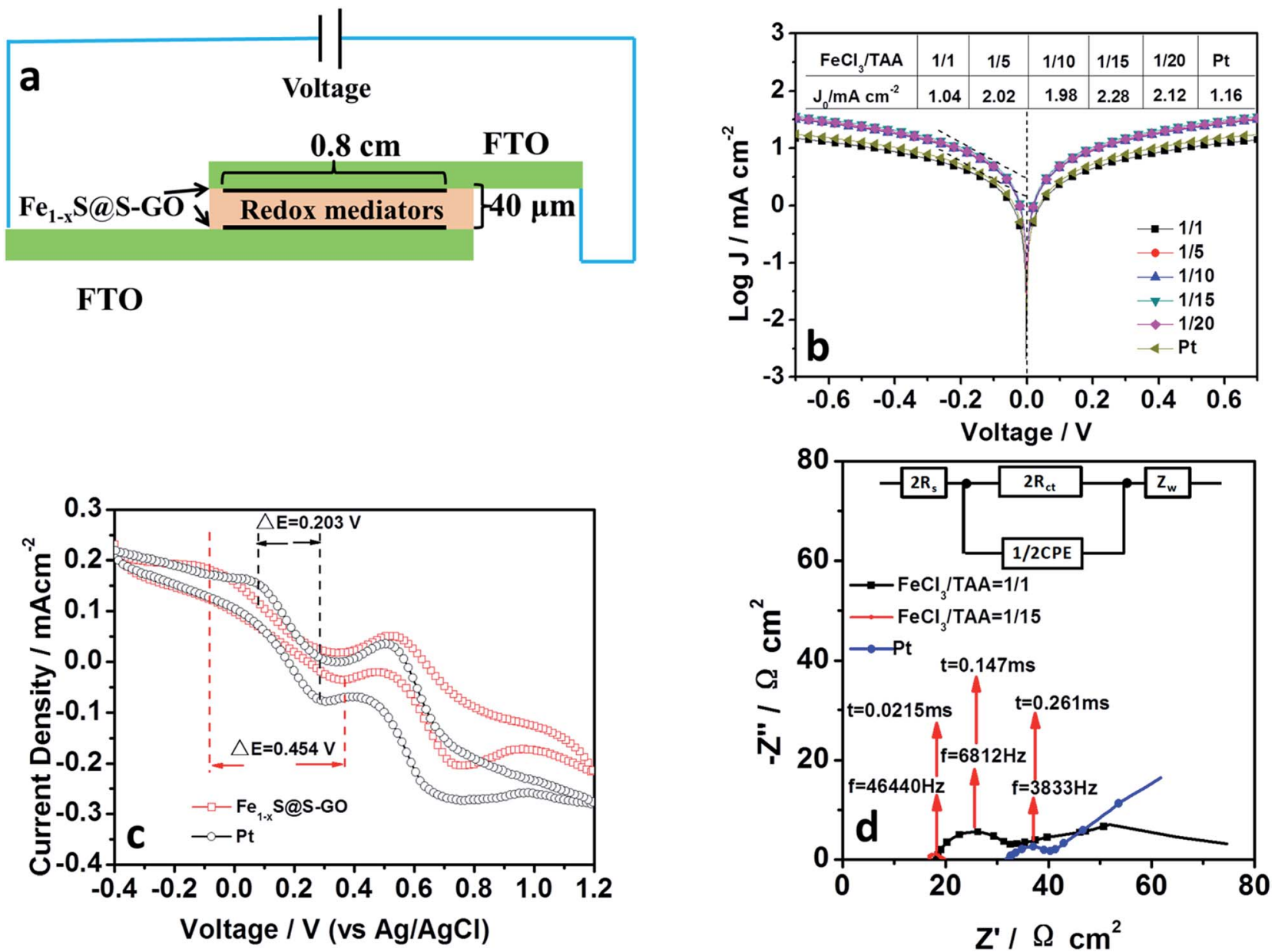

Fig. 4 (a) Schematic illustration and electrochemical properties of symmetrical cells based on the Fe ${ }_{1-x}$ SaS-GO-NMC cathode (cathode/liquid electrolyte $\left(\mathrm{I}_{3}{ }^{-} / \mathrm{I}^{-}\right)$/cathode) under dark and Pt-based devices taken as a reference; (b) Tafel polarization curves of symmetrical cells fabricated with two identical $\mathrm{Fe}_{1-x} \mathrm{SCS}-\mathrm{GO}-\mathrm{NMC}$ cathodes; mole ratios of $\mathrm{FeC}_{3} / \mathrm{TAA}=1 / 1,1 / 5,1 / 10,1 / 15,1 / 20$ (the inset table gives the values of the exchange current density $\mathrm{J}_{0}$ ); (c) $\mathrm{CV}$ curves of the $\mathrm{Fe}_{1-x} \mathrm{~S} \mathrm{CS}-\mathrm{GO}-\mathrm{NMC}$ (mole ratio of $\mathrm{FeCl}_{3} / \mathrm{TAA}=1 / 15$ ) cathode measured by a three-electrode system in liquid electrolyte $\left(\mathrm{I}_{3}^{-} / \mathrm{I}^{-}\right)$; (d) EIS of symmetrical cells fabricated with two identical $\mathrm{Fe}_{1-x} \mathrm{~S} @ \mathrm{~S}-\mathrm{GO}-\mathrm{NMC}$ cathodes (mole ratios of FeCl ${ }_{3}$ $\mathrm{TAA}=1 / 1,1 / 15)$ under bias voltage with the open voltage corresponding to photovoltaic devices. 
Table 2 Average photovoltaic parameters of DSCs based on Fe ${ }_{1-x} \mathrm{~S} @ \mathrm{~S}-\mathrm{GO}-\mathrm{NMC}$ and Pt cathodes and EIS parameters of the symmetrical cells

\begin{tabular}{|c|c|c|c|c|c|c|c|}
\hline Cathode & $V_{\mathrm{oc}}(\mathrm{V})$ & $J_{\mathrm{sc}}\left(\mathrm{mA} \mathrm{cm}{ }^{-2}\right)$ & $\mathrm{FF}$ & PCE (\%) & $R_{\mathrm{S}}\left(\Omega \mathrm{cm}^{2}\right)$ & $R_{\mathrm{ct}}\left(\Omega \mathrm{cm}^{2}\right)$ & $Z_{\mathrm{N}}\left(\Omega \mathrm{cm}^{2}\right)$ \\
\hline $\mathrm{Fe}_{1-x} \mathrm{~S} @ S-G O-\mathrm{NMC}^{a}$ & $0.72 \pm 0.01$ & $13 \pm 1$ & $0.72 \pm 0.02$ & $6.8 \pm 0.3$ & 16.75 & 2.59 & 44.06 \\
\hline Pyrolytic Pt & $0.71 \pm 0.01$ & $12.1 \pm 0.6$ & $0.78 \pm 0.01$ & $6.7 \pm 0.4$ & 32.16 & 9.17 & 132.80 \\
\hline
\end{tabular}

${ }^{a} \mathrm{Fe}_{1-x} \mathrm{~S} @ \mathrm{~S}-\mathrm{GO}-\mathrm{NMC}$ were synthesized with a mole ratio of $\mathrm{FeC}_{3} / \mathrm{TAA}=1 / 15$.

electron transfer and for the regeneration of the redox mediator; this property in turn increases the solar-to-electrical conversion efficiency of the corresponding photovoltaic devices. Fig. 4c shows cyclic voltammograms of $\mathrm{Fe}_{1-x} \mathrm{~S} @ S-G O-N M C$ synthesized with a mole ratio of $\mathrm{FeCl}_{3} / \mathrm{TAA}=1 / 15$ and $\mathrm{Pt}$ for the $\mathrm{I}^{-} / \mathrm{I}_{3}{ }^{-}$ redox couple. Curves obtained with the $\mathrm{Fe}_{1-x} \mathrm{~S} @ \mathrm{~S}-\mathrm{GO}-\mathrm{NMC}$ and a Pt cathode exhibited two pairs of redox peaks. The redox peak at low potential was ascribed to the reaction: $\mathrm{I}_{3}{ }^{-}+2 \mathrm{e}^{-} \rightarrow 3 \mathrm{I}^{-} .{ }^{25}$ The reduction potential and the oxidation potential obtained with $\mathrm{Fe}_{1-x} \mathrm{~S} @ S-G O-N M C$ were $-0.085 \mathrm{~V}$ (vs. Ag/AgCl in saturated potassium chloride) and $0.369 \mathrm{~V}(v s . \mathrm{Ag} / \mathrm{AgCl}$ in saturated potassium chloride), respectively. The reduction potential and oxidation potential obtained under the same conditions with $\mathrm{Pt}$ were $0.078 \mathrm{~V}$ and $0.281 \mathrm{~V}$. The separation between anodic and cathodic peaks $(\Delta E)$ is inversely proportional to the thermodynamic possibility of the above redox reaction. Interestingly, the $\Delta E$ value for $\mathrm{Fe}_{1-x} \mathrm{~S} @ S-G O-N M C(0.454 \mathrm{~V})$ was higher than that for $\mathrm{Pt}(0.203 \mathrm{~V})$, which may explain why the photovoltaic devices based on an $\mathrm{Fe}_{1-x} \mathrm{~S} @ S-G O-N M C$ cathode delivered a lower fill factor $(0.72 \pm 0.02)$ compared to the Pt cathode $(0.78 \pm 0.01)$, as shown in Table 2. EIS was carried out to reveal the inherent interface resistance, as shown in Fig. 4d. The arc at high frequency depends on the charge transfer resistance $\left(R_{\mathrm{ct}}\right)$ at the interface between the cathode and the electrolyte. This parameter reflects the performance of the cathode material. The point of intersection between the plot at high frequency and the real

\section{Light-harvesting antenna $\quad \mathrm{Fe}_{1-\mathrm{x}} \mathrm{S} @ \mathrm{~S}-\mathbf{G O}$ cathode}
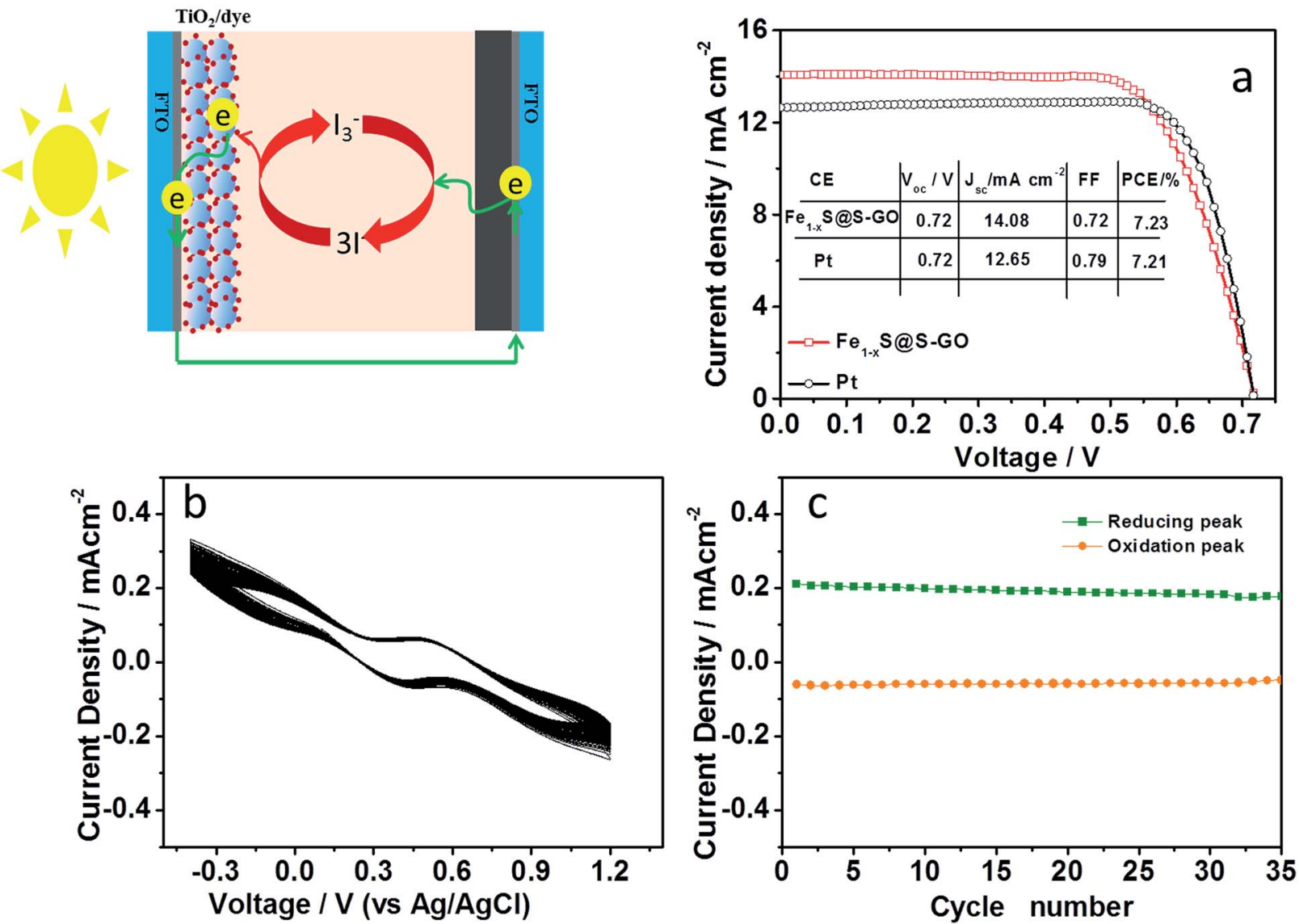

Fig. 5 (a) Schematic illustration and solar-to-electrical conversion properties of DSCs based on the Fe ${ }_{1-x} \mathrm{~S} @ \mathrm{~S}-\mathrm{GO}-\mathrm{NMC}$ cathode under AM1.5, $100 \mathrm{~mW} \mathrm{~cm}^{-2}$ simulated illumination. Pt-based devices are also shown as a reference (the inset table gives the values of the best photovoltaic parameters); (b) stability of the $\mathrm{Fe}_{1-x} \mathrm{~S} \mathrm{SS}-\mathrm{GO}-\mathrm{NMC}$ cathode measured by a three-electrode system in $\mathrm{I}_{3}^{-} / \mathrm{I}^{-}$liquid electrolyte; (c) the values of the redox current density in each cycle of the CV plots. 
axis of the Nyquist plot gives the series resistance $\left(R_{\mathrm{S}}\right)$. The values of the EIS parameters were obtained by fitting Nyquist plots with the Z-view software according to an equivalent circuit diagram (Fig. 4d, inset). The fitting results of the Nyquist plots are listed in Table 2 . The $R_{\text {ct }}$ of symmetrical cells based on FeS@S-GO-NMC (synthesized with mole ratios of $\mathrm{FeCl}_{3} / \mathrm{TAA}=$ $1 / 1$ and 1/15) and a Pt cathode were 16.17, 2.59 and $9.17 \Omega \mathrm{cm}^{2}$, respectively. The reciprocal of the highest frequency $(f)$ of the top of the arc corresponds to the charge exchange resistance representing the reaction time constant $(\tau)$ of the reactant at the cathode surface. The smaller the time constant, the faster the reaction. The value $(0.0215 \mathrm{~ms})$ of $\tau$ obtained with the $\mathrm{Fe}_{1-x} \mathrm{~S} @ \mathrm{~S}$ GO-NMC cathode (synthesized with a mole ratio of $\mathrm{FeCl}_{3} / \mathrm{TAA}=$ 1/15) was smaller than those obtained with $\mathrm{Pt}$ and $\mathrm{Fe}_{1-x} \mathrm{~S} @ \mathrm{GO}-$ NMC (synthesized with a mole ratio of $\mathrm{FeCl}_{3} / \mathrm{TAA}=1 / 1$ ). Thus, the $\mathrm{Fe}_{1-x} \mathrm{~S} @ S-G O-N M C$ (synthesized with a mole ratio of $\mathrm{FeCl}_{3} / \mathrm{TAA}=1 / 15$ ) electrode exhibits a fast electron exchange process occurring at the interface between the reaction and the cathode. In addition, the $Z_{\mathrm{N}}$ of symmetrical cells based on $\mathrm{Fe}_{1-x} \mathrm{~S} @ S-G O-N M C$ (synthesized with a mole ratio of $\left.\mathrm{FeCl}_{3} / \mathrm{TAA}=1 / 1\right)$ is $44.06 \Omega \mathrm{cm}^{2}$, which is smaller than that of a Pt cathode $\left(132.80 \Omega \mathrm{cm}^{2}\right)$. This indicates that the channels formed by $2 \mathrm{D}$ lamellar graphene are beneficial for the diffusion of the electrolyte, which makes the diffusion resistance $\left(Z_{\mathrm{N}}\right)$ smaller. From the analysis of CV, Tafel and EIS results, we can see that the $\mathrm{Fe}_{1-x} \mathrm{~S} @ S-G O-N M C$ cathode exhibited excellent electrocatalytic performance, which in turn promoted the performance of the corresponding photovoltaic devices.

The photovoltaic performance was investigated by characterizing DSCs based on an $\mathrm{Fe}_{1-x} \mathrm{~S} @$ S-GO (synthesized with a mole ratio of $\mathrm{FeCl}_{3} / \mathrm{TAA}=1 / 15$ ) cathode under $\mathrm{AM}$ 1.5, $100 \mathrm{~mW} \mathrm{~cm} \mathrm{~cm}^{-2}$ simulated illumination (schematic diagrams shown in Fig. 5). For each cathode, we fabricated four DSCs devices and determined the mean photovoltaic performance. The detailed photovoltaic parameters are summarized in Table 2. Fig. 5a shows the best photocurrent density with respect to voltage ( $J-V$ curve) for the DSCs in each group. The DSCs based on the $\mathrm{Fe}_{1-x} \mathrm{~S} @ S-G O-N M C$ cathode showed a solar-to-electrical conversion efficiency of $7.23 \%$ with an open circuit voltage $\left(V_{\mathrm{oc}}\right)$ of $0.72 \mathrm{~V}$, a short circuit current density $\left(J_{\mathrm{sc}}\right)$ of $14.08 \mathrm{~mA} \mathrm{~cm} \mathrm{~cm}^{-2}$ and a fill factor $(\mathrm{FF})$ of 0.72 . The conversion efficiency based on the $\mathrm{Fe}_{1-x} \mathrm{~S} @ S-G O-N M C$ cathode is nearly the same as that obtained from DSCs based on pyrolytic Pt cathodes (7.21\%). Although the device is very similar to a tandem DSC, we did not find that the value of $V_{\mathrm{oc}}$ in the device based on the $\mathrm{Fe}_{1-x} \mathrm{~S} @ \mathrm{~S}$ GO-NMC cathode was significantly higher than from the one obtained with the reference Pt. Therefore, the excellent device performance obtained with the $\mathrm{Fe}_{1-x} \mathrm{~S}$ @S-GO-NMC cathode is ascribed to the excellent electrocatalytic activity of the composite material, which could effectively recycle the redox mediator and reduce the over-potential. In addition, an investigation of the stability of $\mathrm{Fe}_{1-x} \mathrm{~S} @ \mathrm{~S}-\mathrm{GO}-\mathrm{NMC}$ in $\mathrm{I}_{3}{ }^{-} / \mathrm{I}^{-}$liquid electrolyte was carried out, as shown in Fig. 5b and c. The changes in the potentials and current density for the redox peaks in each cycle of the $\mathrm{CV}$ plots were not obvious. The results showed that the $\mathrm{Fe}_{1-x} \mathrm{~S} @ S-G O-N M C$ exhibited good stability in $\mathrm{I}_{3}{ }^{-} / \mathrm{I}^{-}$liquid electrolyte.

\section{Conclusions}

In conclusion, we synthesized a nano-micro composite composed of $\mathrm{Fe}_{1-x} \mathrm{~S}$ nanoparticles decorated on sulfur-doped graphene oxide sheets by a one-step hydrothermal method. Compared to $\mathrm{Fe}_{1-x} \mathrm{~S}$ agglomerated particles, GO sheets in NMC obviously prevented the aggregation of $\mathrm{Fe}_{1-x} \mathrm{~S}$ nanoparticles. DSCs based on an $\mathrm{Fe}_{1-x} \mathrm{~S} @ S-G O-N M C$ cathode achieved the highest reported solar-to-electrical conversion efficiency up to $7.23 \%$ for photoelectrochemical cell. The superior performance of the photoelectrochemical device based on $\mathrm{Fe}_{1-x} \mathrm{~S} @ \mathrm{~S}-\mathrm{GO}-$ NMC was attributed to the good electrocatalytic performance of the material. We hope that our work here will be of great interest for fundamental research and for practical applications of $\mathrm{FeS}$ or $\mathrm{FeS}_{2}$ and their composites in the solar splitting of water, artificial photoelectrochemical cells, and electrocatalytic applications.

\section{Conflicts of interest}

There are no conflicts to declare.

\section{Acknowledgements}

This work was financially supported by Shandong Province Natural Science Foundation (Grant No. ZR2016BQ20; BS2015NJ013; ZR2014BQ010; ZR2016BQ21), Colleges and universities in Shandong Province science and technology projects (Grant No. J16LC05), Science and Technology Innovation Foundation for the University or College Students (Grant No. 26312160502), National Science and Technology Innovation Foundation for the University or College Students (Grant No. 201510447021), Research Fund for the Doctoral Program of Liaocheng University (Grant No. 31805), National Natural Science Foundation of China (Grant No. 21503104; 21601078, 21401095), National Basic Research Program of China (Grant No. 2011CBA00701).

\section{Notes and references}

1 D. Tshala-Katumbay, J. C. Mwanza, D. S. Rohlman, G. Maestre and R. B. Oria, A global perspective on the influence of environmental exposures on the nervous system, Nature, 2015, 527, S187-S192.

2 J. Tollefson, Energy crisis upsets platinum market, Nature, 2008, 451, 877.

3 B. Obama, The irreversible momentum of clean energy, Science, 2017, 355, 126-129.

$4 \mathrm{H}$. C. Jin, et al., Photothermal conversion efficiency of nanofluids: An experimental and numerical study, Sol. Energy, 2016, 139, 278-289.

5 A. Polman, M. Knight, E. C. Garnett, B. Ehrler and W. C. Sinke, Photovoltaic materials: Present efficiencies and future challenges, Science, 2016, 352, aad4424.

6 N. S. Lewis, Developing a scalable artificial photosynthesis technology through nanomaterials by design, Nat. Nanotechnol., 2016, 11, 1010-1019. 
7 Y. K. Chen, S. Hu, C. X. Xiang and N. S. Lewis, A sensitivity analysis to assess the relative importance of improvements in electrocatalysts, light absorbers, and system geometry on the efficiency of solar-fuels generators, Energy Environ. Sci., 2015, 8, 876-886.

$8 \mathrm{H}$. Zhou, et al., Interlaced $\mathrm{W}_{18} \mathrm{O}_{49}$ nanofibers as a superior catalyst for the counter electrode of highly efficient dyesensitized solar cells, J. Mater. Chem. A, 2014, 2, 4347-4354.

$9 \mathrm{~J}$. Luo, et al., Water photolysis at $12.3 \%$ efficiency via perovskite photovoltaics and Earth-abundant catalysts, Science, 2014, 345, 1593-1596.

10 Y. Tachibana, L. Vayssieres and J. R. Durrant, Artificial photosynthesis for solar water-splitting, Nat. Photonics, 2012, 6, 511-518.

11 L. L. Quan, et al., A new in situ preparation method to FeS counter electrode for quantum dots-sensitized solar cells, J. Power Sources, 2014, 272, 546-553.

12 H. F. Geng, et al., Electrochemical Growth of FeS on Threedimensional Carbon Scaffold as the High Catalytic and Stable Counter Electrode for Quantum Dot-sensitized Solar Cells, Electrochim. Acta, 2015, 182, 1093-1100.

$13 \mathrm{H}$. F. Geng, et al., FeS/nickel foam as stable and efficient counter electrode material for quantum dot sensitized solar cells, J. Power Sources, 2015, 281, 204-210.

14 J. H. Huo, M. Zheng, Y. G. Tu and J. H. Wu, Highperformance and transparent counter electrodes based on polypyrrole and ferrous sulfide nanoparticles for dyesensitized solar cells, J. Mater. Sci.: Mater. Electron., 2016, 27, 5680-5685.

15 M. Batmunkh, et al., Sulfur-Doped Graphene with Iron Pyrite $\left(\mathrm{FeS}_{2}\right)$ as an Efficient and Stable Electrocatalyst for the Iodine Reduction Reaction in Dye-Sensitized Solar Cells, Solar RRL, 2017, 1, 6 .

16 L. Kavan, Exploiting Nanocarbons in Dye-Sensitized Solar Cells. Making and Exploiting Fullerenes, Graphene, and Carbon Nanotubes, Topics in Current Chemistry-Series, 2014, vol. 348, pp. 53-93.

17 L. Kavan, J. H. Yum and M. Graetzel, Graphene-based cathodes for liquid-junction dye sensitized solar cells:
Electrocatalytic and mass transport effects, Electrochim. Acta, 2014, 128, 349-359.

18 M. Janani, P. Srikrishnarka, S. V. Nair and A. S. Nair, An indepth review on the role of carbon nanostructures in dyesensitized solar cells, J. Mater. Chem. A, 2015, 3, 1791417938.

19 L. Kavan, P. Liska, S. M. Zakeeruddin and M. Gratzel, Lowtemperature Fabrication of Highly-Efficient, OpticallyTransparent (FTO-free) Graphene Cathode for Co-Mediated Dye-Sensitized Solar Cells with Acetonitrile-free Electrolyte Solution, Electrochim. Acta, 2016, 195, 34-42.

20 L. Kavan, et al., Novel highly active Pt/graphene catalyst for cathodes of $\mathrm{Cu}(\mathrm{II} / \mathrm{I})$-mediated dye-sensitized solar cells, Electrochim. Acta, 2017, 251, 167-175.

$21 \mathrm{~J}$. Yin, et al., Indium- and Platinum-Free Counter Electrode for Green Mesoscopic Photovoltaics through Graphene Electrode and Graphene Composite Catalysts: Interfacial Compatibility, ACS Appl. Mater. Interfaces, 2016, 8, 53145319.

22 L. Kavan, Electrochemistry and dye-sensitized solar cells, Current Opinion in Electrochemistry, 2017, 2, 88-96.

23 K. Shehzad, Y. Xu, C. Gao and X. F. Duan, Three-dimensional macro-structures of two-dimensional nanomaterials, Chem. Soc. Rev., 2016, 45, 5541-5588.

$24 \mathrm{H}$. Zhou, et al., Earth-abundant and nano-micro composite catalysts of $\mathrm{Fe}_{3} \mathrm{O}_{4} @$ reduced graphene oxide for green and economical mesoscopic photovoltaic devices with high efficiencies up to 9\%, J. Mater. Chem. A, 2016, 4, 67-73.

$25 \mathrm{H}$. Zhou, et al., Printable fabrication of Pt-and-ITO free counter electrodes for completely flexible quasi-solid dyesensitized solar cells, J. Mater. Chem. A, 2013, 1, 3932-3937.

26 K. Laajalehto, I. Kartio and P. Nowak, XPS study of clean metal sulfide surfaces, Appl. Surf. Sci., 1994, 81, 11-15.

$27 \mathrm{H}$. Binder, Investigations on nature of chemical bonds in iron-sulfur compounds using X-ray photoelectron spectroscopy, Z. Naturforsch., B: J. Chem. Sci., 1973, 28, 255-262. 